\title{
Radiodiagnostic method for studying swimbladder inflammation caused by Anguillicola crassus (Nematoda: Dracunculoidea)
}

\author{
A. Beregi ${ }^{1}$, K. Molnár ${ }^{2}$, L. Békési ${ }^{3}$, Cs. Székely ${ }^{2}$ \\ ${ }^{1}$ Department of Internal Medicine and ${ }^{3}$ Department of Parasitology and Zoology, University of Veterinary Science, \\ POB 2, H-1400 Budapest, Hungary
}

${ }^{2}$ Veterinary Medical Research Institute, Hungarian Academy of Sciences, Hungária krt. 21, H-1143 Budapest, Hungary

\begin{abstract}
The nematode Anguillicola crassus appeared in Europe about 15 yr ago, and has subsequently become recognised as a cause of major pathological lesions in the swimbladder of the European eel Anguilla anguilla. The radiographic method reported in this paper showed be a useful complement to diagnostic methods that have so far been based exclusively on fish dissection. Using this method, the infection of the swimbladder and the severity of its pathological changes can be assessed in a reliable manner without causing damage to the fish. By analysing radiographs of 45 eels from Lake Balaton, 5 stages of swimbladder lesions were distinguished. The method enables the examiner to draw conclusions on the air, worm and exudate content of the swimbladder; however, data on thickening of the swimbladder wall can be obtained only indirectly. The radiograph also provides information on the air and worm content of the pneumatic duct. Results obtained by radiography showed good agreement with dissection findings. Radiographic results are compared with pathological findings obtained from fish dissections separately for each severity grade of infection.
\end{abstract}

KEY WORDS: Radiography · Eel - Swimbladder - Anguillicola crassus - Nematode P Parasite

\section{INTRODUCTION}

Anguillicola crassus Kuwahara, Nimi et Itagaki, 1974 (Camallanata, Dracunculoidea, Anguillicolidae), a nematode parasitizing the swimbladder of different eel species, was brought into Europe from Eastern Asia in the 1980s. The parasite causes hardly any lesions in its original host, Anguilla japonica (see Egusa 1979), but has proved to be pathogenic to the Anguilla anguilla populations of European waters (Haenen et al. 1989, Sprengel \& Lüchtenberg 1991, Höglund et al. 1992, Hartmann 1994, Barus 1995).

The European literature abounds in data on the prevalence, biology and epidemiology of Anguillicola crassus (Taraschewski et al. 1987, Kennedy \& Fitch 1990, Køie 1991, Thomas \& Ollevier 1992, Moravec 1996, Székely 1996).

The appearance of Anguillicola crassus in Hungary was first described by Székely et al. (1991). The mass

\footnotetext{
•E-mail: aberegiens.univet.hu
}

mortality of infected eels which first occurred in Lake Balaton in 1991, and the related pathological investigations, were reported by Molnár et al. (1991) and Csaba et al. (1993). The pathological changes caused by this nematodosis have been thoroughly studied by Haenen et al. (1989), van Banning \& Haenen (1990), Molnár et al. (1993), and Molnár (1994). They established that the direct damage done by $A$. crassus arose from the blood-sucking of mature worms as well as from changes produced in the swimbladder wall by the migration of larvae. Changes included serous infiltration, haemorrhages, formation of parasitic nodules, and inflammatory cell proliferation, which eventually caused substantial thickening of the swimbladder wall. According to the above authors, besides changes of the swimbladder wall, the number of helminths and the amount of exudate and debris present in the swimbladder lumen are also important factors for evaluating the severity of infection. Csaba et al. (1993) and Hartmann (1993) scored the swimbladder lesions of affected eels by severity grade based upon the gross 
pathological findings. Changes in the gaseous components of the swimbladder were studied by Würtz et al. (1995), who pointed out that oxygen content markedly decreased as a result of the helminthosis.

Data on the anatomy and histological structure of the intact eel swimbladder as well as of the pneumatic duct connecting the swimbladder with the gut can be found in the works of Dorn (1961) as well as Clarke \& Witkomb (1980).

In the field of pisciculture, radiography has already been used by several authors for studying anatomical relationships (Smith \& Smith 1994), for determining the damage caused by parasites (Langdon 1987, Treasurer 1992), and for proving the toxic effects exerted by chemicals (Wells \& Cowan 1982). Radiographic methods have recently acquired an important role in studies of fish nutrition (Carter et al. 1995). According to Love \& Lewbart (1997), radiographic techniques are suitable for demonstrating different pathological changes and for studying diseases of the swimbladder. However, no report could be found in the literature on radiodiagnostic studies of swimbladder diseases in cultured fish species.

In view of these facts, the objective of this work was to complement the hitherto applied fish pathological and parasitological studies by a new investigational method which spares the life of the fish, can be interpreted immediately, and has diagnostic value. The method is based on the radiodiagnostic principle that body parts (organs) filled with air are radiotransparent and thus readily discernible as dark areas on the radiograph.
The eels were immobilised for radiography in 3 different ways: (1) in MS 222 (tricaine methanesulfonate, Sigma) solution of 100 to $150 \mathrm{mg} \mathrm{l}^{-1}$ concentration (Stoskopf 1993); (2) by cooling in icy water for 5 to 10 min (Haenen et al. 1996); (3) by physical immobilisation, i.e. holding the eels in position in a towel.

A TUR DE 38 type mobile X-ray apparatus (Germany) was used, with the following parameters: tube voltage 50 to $100 \mathrm{kV}$, electronic time switch 0.04 to $8 \mathrm{mAs}$. The radiographs were taken on $18 \times 24$ size Kodak T-MAT S/RA X-ray film. The exposure values varied between 55 and $65 \mathrm{kV}$, at $0.1 \mathrm{~s}$ and $2 \mathrm{mAs}$, in proportion to the body mass. The fish were placed directly onto the cassette which was covered with polyethylene foil. Two-way radiographs were taken in all cases, in laterolateral (LL) and dorsoventral (DV) position.

After radiography, identification marks were made on the eels' skin, their body length was measured after anaesthesis, and then the fish were bled and subjected to parasitological dissection. The swimbladder and the pneumatic duct starting from it were dissected out; then drawings were made of each swimbladder. Specimens that could be regarded as typical cases were photographed before the swimbladder was opened (see Fig. 6). Subsequently the swimbladders were cut open (see Fig. 7), the numbers of worms as well as the amount of exudate and worm debris present in their lumen were recorded, and the thickness of the swimbladder wall was determined. The dissection results were compared with the radiographic findings

\section{MATERIALS AND METHODS}

The fish used in the study were obtained from different sources. Eels with uninfected swimbladders were used as control. Five such fish of 30 to $40 \mathrm{~cm}$ body length originated from an intensive eel farm and 5 specimens of 60 to $70 \mathrm{~cm}$ body length were collected from backwaters of the river Tisza, which was still free of Anguillicola infection.

Anguillicola crassus infected eels measuring 60 to $74 \mathrm{~cm}$, originating from different regions of Lake Balaton, were examined on 8 occasions in 1996 and 1997. At that time a total of 45 infected eels were subjected to radiographic examination.

The fish intended for radiography were transported to the laboratory alive, and then were allowed at least $2 \mathrm{wk}$ of acclimatisation in aquaria to avoid the effect of stress caused by the transport.

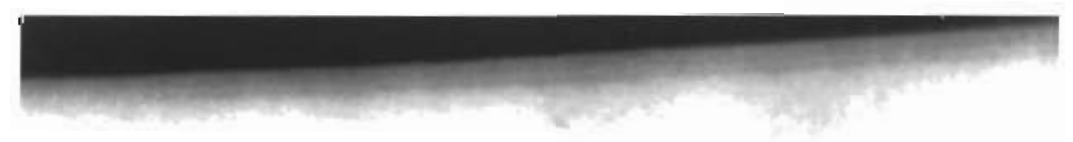

Grade 1. The shape of the swimbladder of healthy eels (Fig. 1) is clearly outlined on the radiographs. The swimbladder gives a homogeneous radiographic shadow under the spinal column despite the fact that

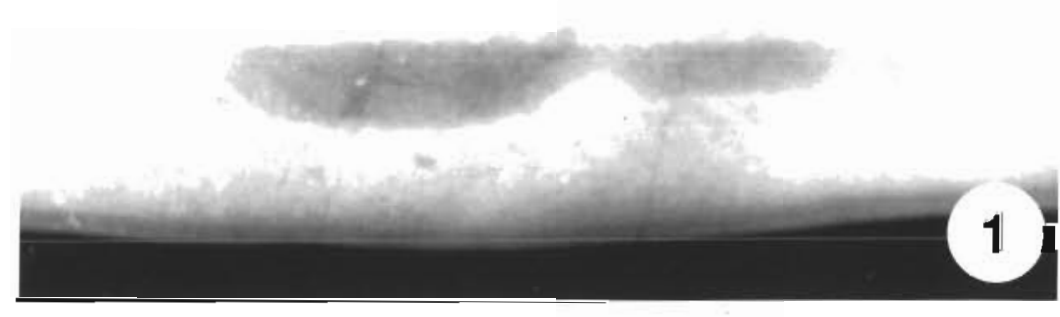

Fig. 1 Anguilla anguilla. Radiograph of the swimbladder of an eel free from Anguillicola crassus infection. Lateral view. The narrowing in the middle arises from the position of the gas glands. $\times 1.5$ 


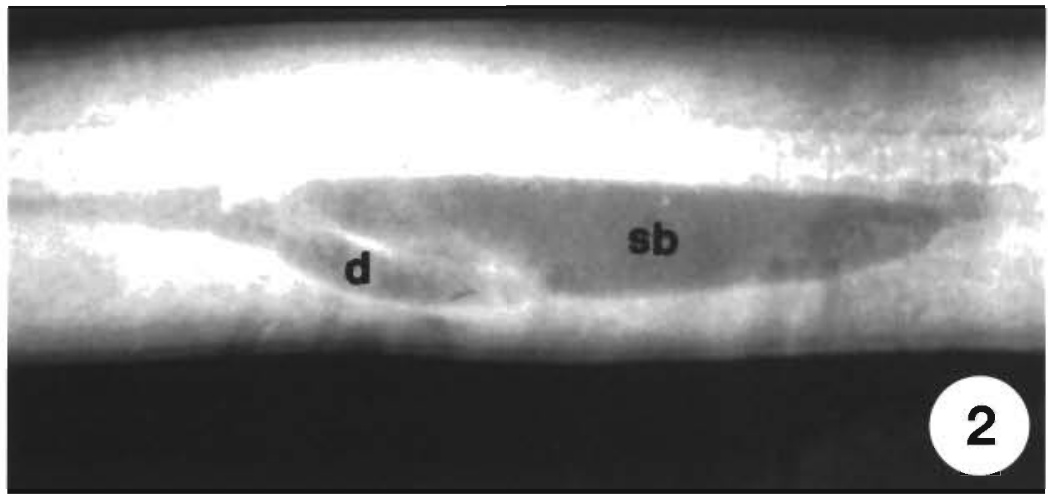

Fig. 2. Anguilla anguilla. Radiograph of a swimbladder stage representing incipient or regenerating anguillicolosis. Both the swimbladder (sb) and the pneumatic duct (d) are filled with air. No shadows of worms can be seen. $\times 1$ of the swimbladder are faintly discernible.

On dissection, a swimbladder representing this stage of infection is apparently normally filled with air; its wall is slightly opacified and sometimes contains haemorrhages but does not exceed $1 \mathrm{~mm}$ in thickness. The lumen usually contains only a few worms of small size. In some cases, worms occur also in the lumen of the air-filled pneumatic duct (see Figs. 6 b \& 7 b)

Grade 3. In more severe cases the $X$-ray shadow of the swimbladder is deformed and its length equals only that of 12 to 14 vertebrae. Because of the worms present in the swimblad-

the shadow of the ribs is projected onto it. Its size is proportional to the body size of the fish and usually occupies 15 intervertebral spaces. The wall of the swimbladder can hardly be seen, or cannot be seen at all. The sac is divided into 2 parts by the compact substance of the paired gas glands (rete mirabile) or by their shadow (Dorn 1961).

On dissection, the swimbladder of infection-free eels is transparent and thin-walled, with the wall thickness not exceeding $0.3 \mathrm{~mm}$. The pneumatic duct does not contain air. The swimbladder collapses after opening (see Figs. 6a \& 7 a).

Grade 2. In the mildest case of swimbladder changes, the radiographic picture of the swimbladder of eels that have recovered from, and regenerated after, a primary infection and have possibly become reinfected by young worms resembles that of the healthy swimbladder; however, the swimbladder of such eels differs from the intact swimbladder in shape and structure (Fig. 2). In such cases the middle third of the swimbladder is often dilated, and its ends are tapered. The X-ray shadow of the swimbladder is nonhomogeneous. Inside the swimbladder, shadows of varying homogeneity, corresponding to the different inflammatory processes, are outlined. The pneumatic duct is filled with air, its lumen is distinct and its width often reaches that of the swimbladder. The contours of small-sized worms present in the pneumatic duct or in either end der, the radiographic shadow is of cystic structure (Fig. 3A). The pneumatic duct is dilated and contains air. The contours of the worms are often readily discernible both in the swimbladder lumen and in the pneumatic duct (Fig. 3B).

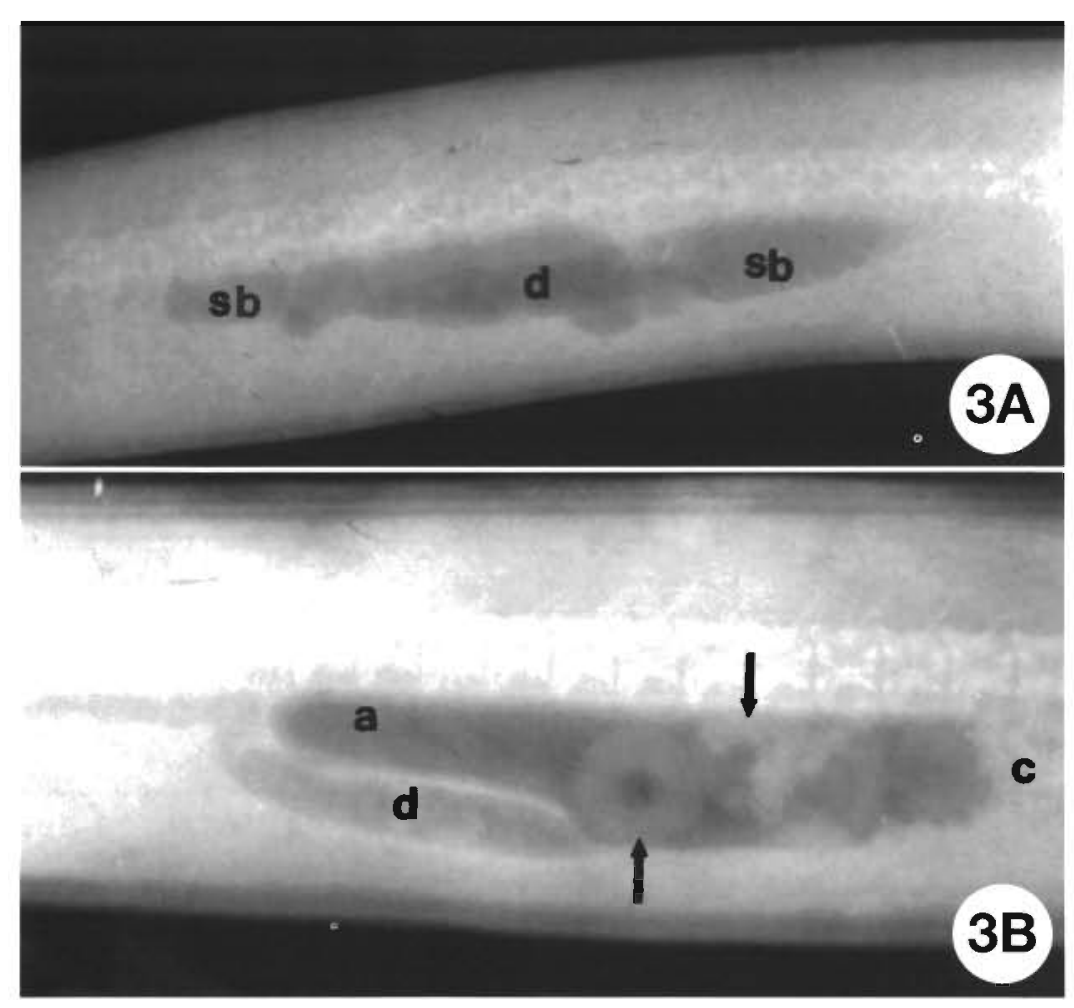

Fig. 3. Anguilla anguilla. Radiographs of the swimbladder of an eel infected with the adult stages of Anguillicola crassus. (A) The helminth-filled swimbladder (sb) shows 'cystic' structure. The darker shade represents the pneumatic duct (d) pressed close to the swimbladder. $\times 1$. (B) Large female worms (arrows) are well visible in the caudal part of the swimbladder tightly packed with worms. The caudal end ( $c$ ) having thickened walls does not give a radiographic shadow. In the anterior part ( $d$ ) of the bladder an air-filled worm-free area can be seen. The dilated, air-filled duct (d) also contains helminths. $\times 1$ 
On dissection, the dilated, air-filled lumen of the swimbladder contains a small amount of exudate and numerous worms, which may produce hollows in the swimbladder wall. Often the dilated lumen of the pneumatic duct also contains worms. The swimbladder wall is opaque and slightly thickened; however, only near the 2 ends of the sac does its thickness reach $2 \mathrm{~mm}$ (see Figs. $6 \mathrm{c} \& 7 \mathrm{c}$ ).

Grade 4. The swimbladder has a narrowed X-ray shadow and its presence is indicated only by a narrowed, occasionally spot-like shadow representing the air contained by the bladder. The shadow of the pneumatic duct is not visible (Fig. 4).

On dissection, one or both ends of the swimbladder are atrophied, and sometimes one of its halves is completely devoid of air. The lumen contains more or less exudate and a few small or dead worms. The swimbladder wall is markedly thickened. Wall thickness may reach 2 to $3 \mathrm{~mm}$ in the middle third and even 3 to
$5 \mathrm{~mm}$ at the ends. The pneumatic duct appears as an airless bundle (see Figs. 6d \& 7 d).

Grade 5. No air content can be detected in the swimbladder. The radiographic shadow of the area shows homogeneous density corresponding to the abdominal organs (Fig. 5).

On dissection, the swimbladder appears markedly shrunken, with a rigid wall, and contains neither air nor any other material (exudate, worms). The swimbladder wall is uniformly and markedly thickened, with a thickness reaching 2 to $5 \mathrm{~mm}$. The duct contains no air and its wall is thin (Figs. 6e \& 7e).

The number of worms found in the swimbladder at dissection was 8.93 on average in the 45 eels examined.

Of the 45 Lake Balaton eels infected with Anguillicola crassus or showing signs of previous infection, 11 fish could be assigned to lesion severity grade 2, 12 to grade 3,15 to grade 4 , and 7 to grade 5 .

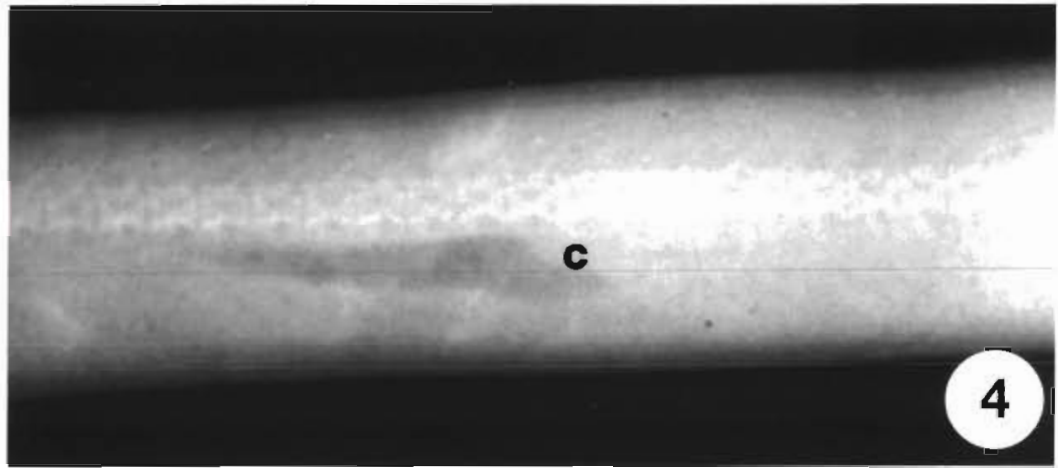

Fig. 4. Anguilla anguilla. Radiograph of a swimbladder having a thickened wall and narrowed lumen as a result of Anguillicola crassus infection. The caudal end (c) of the bladder is devoid of air. The few small worms found in the anterior and middle segments of the bladder at dissection give no observable radiographic shadow. The airless pneumatic duct also gives no shadow. $\times 0.7$

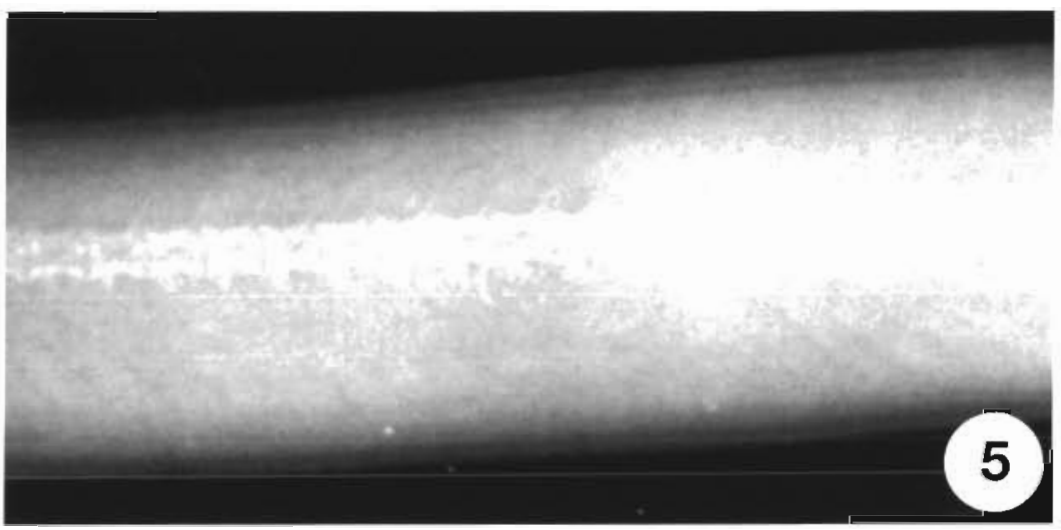

Fig. 5. Anguilla anguilla. Radiograph of a swimbladder devoid of air and having a thickened wall as a result of Anguillicola crassus infection. The swimbladder gives no radiographic shadow. $\times 1$

\section{DISCUSSION}

All 3 methods of immobilisation proved to be suitable for the radiographic analysis. For studies of this type, the simplest method of immobilisation, i.e. manual restraint, is recommended. An evaluation of the posture of fish during radiography revealed that DV radiographs provide less information.

The dissection results showed good agreement with the radiographic findings. Minor differences arose mainly from the escape of air from the dilated pneumatic duct through the free stump during dissection or when the swimbladder was lifted out. This source of error could be eliminated by ligating the end of the pneumatic duct before the duct was separated from the gut. The method enabled us to determine objectively the air content of the swimbladder and to tell whether the bladder was dilated or shrunken. Radiographs provide information primarily about the shape and air content of the swimbladder, but worms present in the swimbladder lumen or in the pneumatic duct are also clearly discernible on them. However, the thickness of the swimbladder wall can only be inferred indirectly from the radiographs. Wall thickening is indi- 


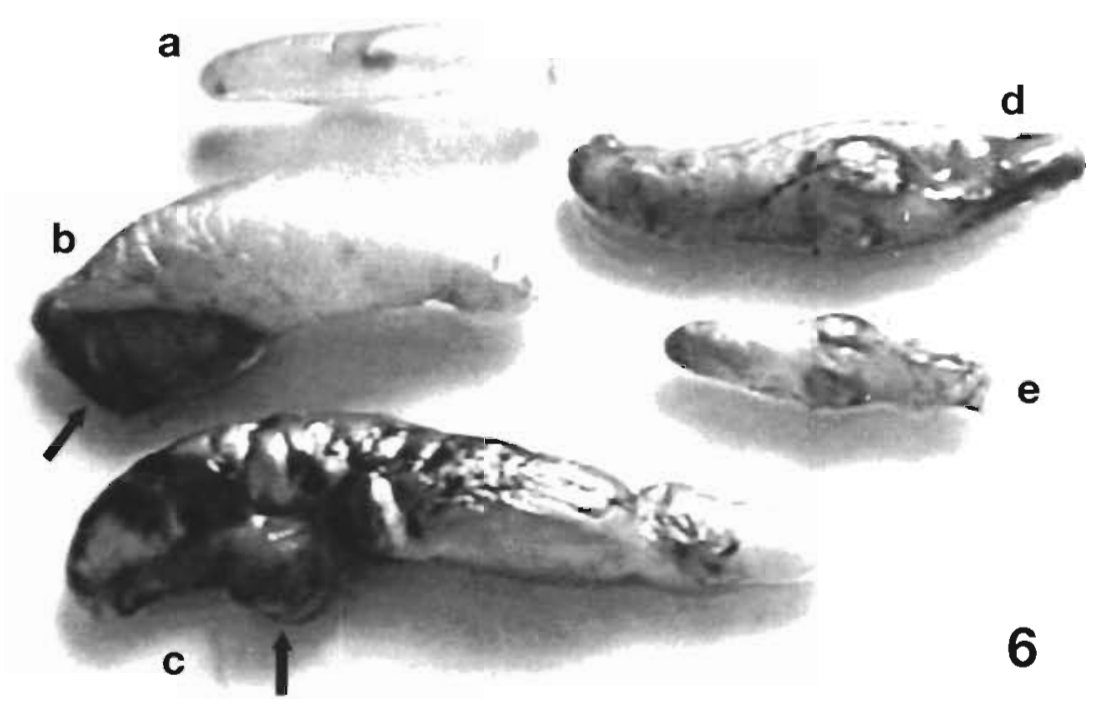

Fig. 6. Anguilla anguilla. Infection-free eel swimbladders and those representing different stages of Anguillicola crassus induced lesions, before opening. (a) Swimbladder of a healthy eel (see Fig. 1). (b) Partially regenerated swimbladder of a helminth-free eel that has recovered from infection (see Fig. 2). A small piece of liver (arrow) adheres to the bladder. (c) Relatively thin-walled swimbladder of an eel massively infected with worms (see Fig. 4). A small piece of liver (arrow) adheres to the bladder (d) Thick-walled eel swimbladder of narrowed lumen (see Fig. 5). (e) Thick-walled, airless swimbladder of an eel (see Fig. 6) $\times 1$
(1994) in earlier years. On the basis of both the radiographic findings and the dissection results, the swimbladder lesions could be assigned to the higher severity grades: most of the eels collected from Lake Balaton showed lesions of severity grades 3 and 4 . No eels free from swimbladder damage could be found in Lake Balaton. In contrast, all eel specimens originating from the backwaters of the river Tisza and from the eel farm had a perfectly intact and helminth-free swimbladder.

Acknowledgements. This work was supported by the Fisheries Fund of the Ministry of Agriculture and the Hungarian Scientific Research Fund (OTKA, project no. T 020044). The authors thank Ms Emese Papp for her help in the fish dissections, as well as the staff of the Balaton Fisheries Company and the crew of cated first of all by the shape of the swimbladder. In the majority of cases, the radiographic image of a bladder dilated at the middle and tapered at both ends meant a substantial wall thickening at the ends of the swimbladder. In some cases, especially in those assigned to severity grades 3 and 4 , one half of the bladder (usually the caudal part) did not give a complete radiographic shadow. In such cases, dissection revealed aggregated worms or worm debris in the given segment. In the majority of the lesions assigned to grade 3 , the pneumatic duct was dilated like the swimbladder and contained worms; in some cases, however, this could not be detected by radiography. In such cases the pneumatic duct proved to be devoid of air and was filled by fluid and worms, unlike grades 4 and 5, when the pneumatic duct was found to be airless both by radiography and by dissection.

The average number of worms found was similar to that observed by Békési et al. (1997), which is less than the worm counts reported by Molnár et al.

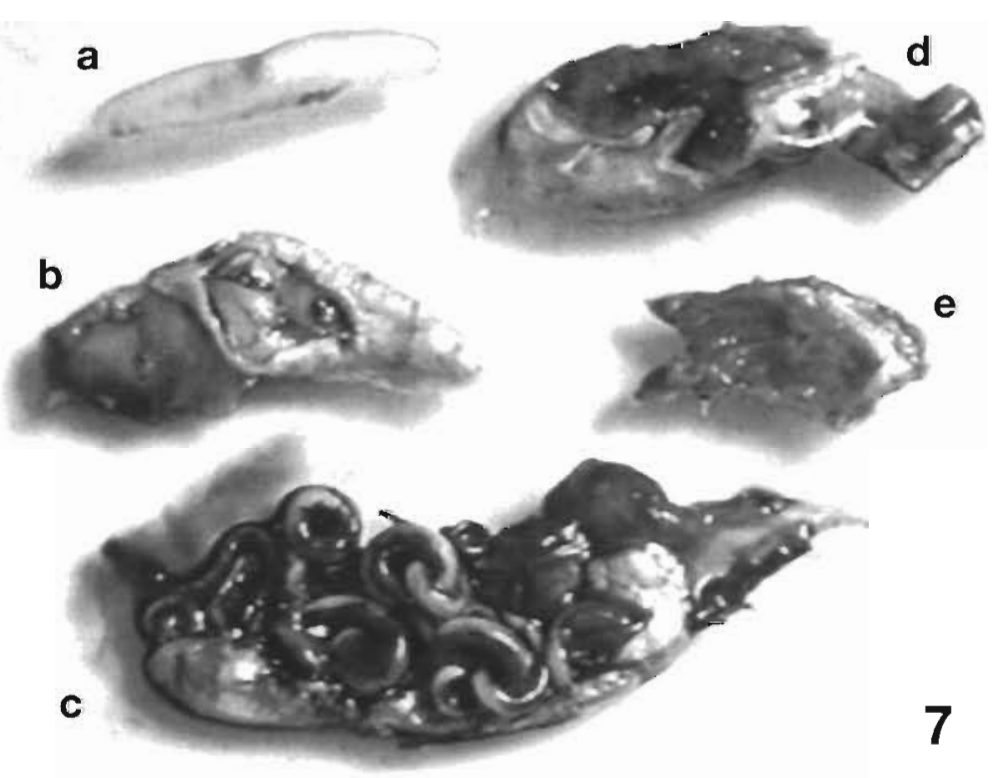

Fig. 7. Anguilla anguilla. Infection-free eel swimbladders and those represent ing different stages of Anguillicola crassus induced lesions, after opening (a) (Unopened) swimbladder of a healthy eel. (b) Partially regenerated swimbladder of a helminth-free eel that has recovered from infection. The relatively thin-walled swimbladder collapsed after opening. (c) Numerous worms emerge from the relatively thin-walled swimbladder (d) Only the anterior part of the thick-walled swimbladder of narrowed lumen contains an air-filled cavity in which only a few and small-sized worms can be found. (e) Thick-walled, airless swimbladder of an eel. $\times 1$ 
the research boat of the Balaton Limnological Research Institute of the Hungarian Academy of Sciences for their help in catching fish for the study. Thanks are also due to the Fisheries Co-operative of Alpar for making available to us infection-free eels

\section{LITERATURE CITED}

Barus V (1995) The nematode Anguillicola crassus - a serious parasite of eel in the Czech Republic. In: Spurny P (ed) Proceedings of the International Conference 'Production of Stock Material in Perspective Fish Species' MUAF, Brno, p 144-150 (in Czech, with English abstract)

Békési L, Hornok S, Székely C (1997) Attempts to analyse Anguillicola crassus infection and the humoral host response in eels (Anguilla anguilla) of Lake Balaton, Hungary. Acta Vet Hung 45:439-445

Carter CG, McCarthy ID, Houlihan DF, Fonseca M, Perera WMK, Sillah ABS (1995) The application of radiography to the study of fish nutrition. J Appl Ichthyol 11:231-739

Clarke AJ, Witkomb DM (1980) A study of the histology and morphology of the digestive tract of the common eel (Anguilla anguilla). J Fish Biol 16:159-1.70

Csaba Gy, Láng M, Sályi G, Ramotsa J, Glávits R, Rátz F (1993) The nematode Anguillicola crassus (Nematoda, Anguillicolidae), and its role in the death of eels in Lake Balaton during 1991. Magyar Állatorvosok Lapja 48:11-24. (in Hungarian, with English abstract)

Dorn E (1961) Über den Feinbau der Schwimmblase von Anguilla vulgaris L. Z Zellforsch 55:849-912

Egusa S (1979) Notes on the culture of the European eel (Anguilla anguilla L.) in Japanese eel-farming ponds. Rapp PV Réun Cons Int Explor Mer 174:51-58

Haenen OLM, Grisez L, De Charleroy D, Belpaire C, Ollevier $F$ (1989) Experimentally induced infections of European eel Anguilla anguilla with Anguillicola crassus (Nematoda, Dracunculoidea) and subsequent migration of larvae. Dis Aquat Org 7:97-101

Haenen OLM, van Wijngaarden TAM, van der Heijden MHT, Höglund J, Cornelissen JBJW, van Leengoed LAMG, Borgstede FHM, van Muiswinkel WB (1996) Effect of experimental infection with different doses of Anguillicola crassus (Nematoda, Dracuncoloidea) on European eel (Anguilla anguilla). Aquaculture 141:41-57

Hartmann F (1994) Untersuchungen zur Biologie, Epidemiologie und Schadwirkung von Anguillicola crassus Kuwahara, Niimi und Itagaki 1974 (Nematoda), einem blutsaugenden Parasiten in der Schwimmblase des europäischen Aals (Anguilla anguilla L.). Berichte aus der Biologie. Verlag Shaker, Aachen, p 1-139

Höglund J, Andersson J, Hardig J (1992) Haematological responses in the European eel. Anguilla anguilla L., to sublethal infestation by Anguillicola crassus in a thermal effluent of the Swedish Baltic. J Fish Dis 15:507-51.4

Kennedy CR, Fitch DJ (1990) Colonization, larval survival and epidemiology of the nematode Anguillicola crassus, parasitic in the eel. Anguilla anguilla, in Britain. J Fish Biol 36:117-131

Køie M (1991) Swimbladder nematodes (Anguillicola spp.) and gill monogeneans (Pseudodactylogyrus spp.) parasitic on the European eel (Anguilla anguilla). J Cons Int Explor Mer 47:391-398

Langdon JS (1987) Spinal curvatures and ancephalotropic myxosporean, Triangula percae sp. nov. (Myxozoa: Ortholineidae), enzootic in redfin perch, Perca fluviatilis .L., in Austrulia. J Fish Dis 10:425-434

Love $v E$, Lewbart GA (1997) Pet fish radiography: technique and case history reports. Vet Radiol Ultrasound 38:24-29

Molnár K (1994) Formation of parasitic nodules in the swimbladder and in the intestinal walls of the eels Anguilla anguilla due to infections with larval stages of Anguillicola crassus. Dis Aquat Org 20:163-170

Molnár K, Székely C, Baska F (1991) Mass mortality of eel in Lake Balaton due to Anguillicola crassus infection. Bull Eur Assoc Fish Pathol 11:211.

Molnár K, Baska F, Csaba G, Glávits R, Székely C (1993) Pathological and histopathological studies of the swimbladder of eel Anguilla anguilla infected by Anguillicola crassus (Nematoda: Dracuncoloidea). Dis Aquat Org 15 41-50

Molnár K, Székely C, Perény̧i M (1994) Dymamics of Anguillicola crassus (Nematoda: Dracunculoided) infection in eels of Lake Balaton. Hungary. Folia Parasitol 41:193-202

Moravec F (1996) Aquatic invertebrates (snails) as new paratenir hosts of Anguillirola crassus (Nematoda: Dracunculoidea) and the role of paratenic hosts in the life cycle of this parasite. Dis Aquat Org 27:237-239

Smith SA, Smith BJ (1994) Xeroradiographic and radiographic anatomy of the channel catfish (Ictalurus punctatus). Vet Radiol Ultrasound 35:384-389

Sprengel G, Lüchtenberg H (1991) Infection by endoparasites reduces maximum swimming speed of European smelt Osmerus eperlanus and European eel Anguilla anguilla. Dis Aquat Org 11:31-35

Stoskopf MK (1993) Clinical examination and procedures. In Stoskopf MK (ed) Fish medicine. Saunders, Philadelphia, p $68-74$

Székely $C$ (1996) Experimental studies on the infectivity of Anguillicola crassus third-stage larvae (Nematoda) from paratenic hosts. Folia Parasitol 43:305-311

Székely C, Láng M, Csaba G (1991) First occurrence of Anguillicola crassus in Hungary. Bull Eur Assoc Fish Pathol 11:192-193

Taraschewski H, Moravec F, Lamah T, Anders K (1987) Distribution and morphology of two helminths recently introduced into European eel populations: Anguillicola crassus (Nematoda, Dracunculoidea) and Paratenuisentis ambiguus (Acanthocephala, Tenuisentidae). Dis Aquat Org 3: $167-176$

Thomas K, Ollevier F (1992) Population biology of Anguillicola crassus in the final host Anguilla anguilla. Dis Aquat Org 14:163-170

Treasurer J (1992) Vertebral anomalies associated with Myxobolus sp. in perch, Perca fluviatilis L., in a Scottish loch. Bull Eur Assoc Fish Pathol 12:61-63

van Banning $P$, Haenen. OLM (1990) Effects of the swimbladder nematode Anguillicola crassus in wild and farmed eel Anguilla anguilla. In: Perkins FO, Cheng TC (eds) Pathology in marine science. Proc 3rd Int Coll on Path in Marine Aquaculture, Gloucester Point, Virginia. Academic Press, New York, p 317-330

Wells DE, Cowan AA (1982) Vertebral dysplasia in salmonids caused by the herbicide trifluralin. Environ Pollut 29 $249-260$

Würtz J, Taraschewski. H, Pelster B (1995) Changes in gas composition in the swimbladder of the European eel (Anguilla anguilla) infected with Angullicola crassus (Nematoda). Parasitology 112:233-238 